\title{
A new camptodactyly syndrome
}

\author{
M BARAITSER \\ From the Clinical Genetics Unit, The Hospital for Sick Children, Great Ormond Street, London
}

SUMMARY A family is reported in which scoliosis and camptodactyly occurred in members over four generations. Additional features were torticollis, fusion of cervical vertebrae, and occasional limitation of joint movement in the upper limbs. Inheritance is autosomal dominant.

Flexion contracture of the proximal interphalangeal joints is known as camptodactyly. As an isolated malformation it affects one in 300 in the population and can be inherited as an autosomal dominant trait with variable expression. ${ }^{1}$ A small number of syndromes is known in which camptodactyly is a major feature. In this report, many members of a family are described who show camptodactyly, scoliosis, and torticollis, a combination that has not been previously reported.

\section{Clinical features}

The pedigree (fig 1) shows members over four generations with the main features transmitted in an autosomal dominant manner. The clinical signs present in each member are listed in table 1. All nine members had scoliosis to a variable degree. In the proband $(\mathrm{V} \cdot 3)$ it was noted in early childhood and, despite adequate treatment, progressed, whereas in the other members of the family the scoliosis varied from mild to severe. Four members needed an orthopaedic operation in an attempt to correct the deformity. Seven of the nine had camptodactyly. Torticollis was present in five and one required

Received for publication 9 April 1981

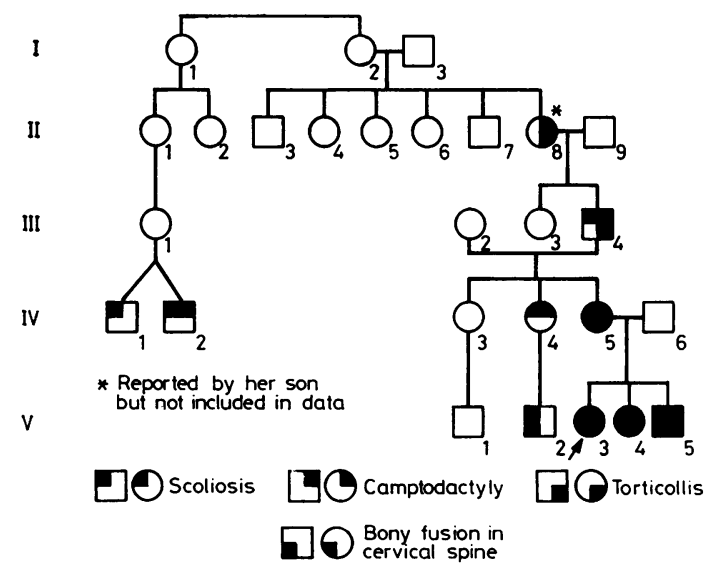

FIG 1 Pedigree of the family

surgical treatment in infancy. At least five members had fusion of cervical vertebrae. One out of nine was severely mentally retarded and this boy $(\mathrm{V} \cdot 5)$ had all the major features of the syndrome. Four members were unable to extend their elbows totally but other joints were not involved.

TABLE 1 Summary of clinical findings

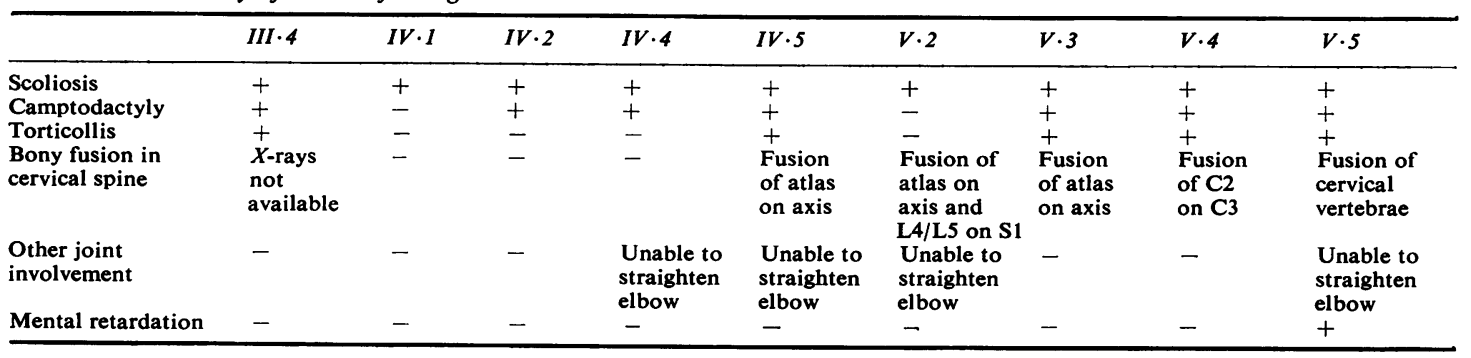




\section{Discussion}

Camptodactyly, scoliosis, and torticollis are the main manifestations of a dominantly inherited syndrome which might occasionally include severe mental retardation. The 'whistling face' syndrome was considered, but this is characterised by camptodactyly with ulnar deviation ('windmill-vane'

(a)

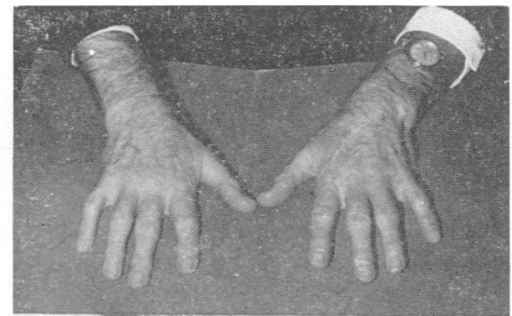

(b)

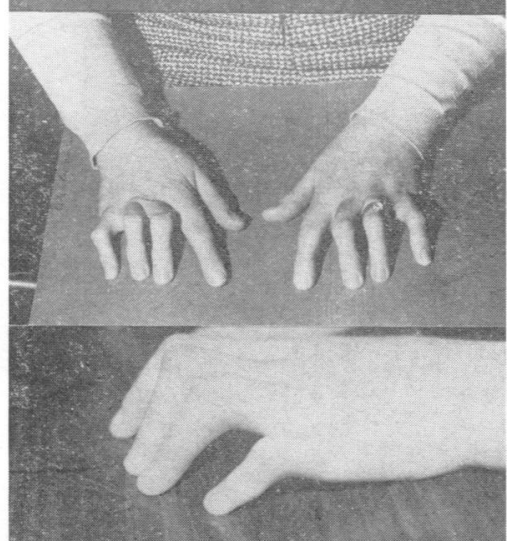

(d)

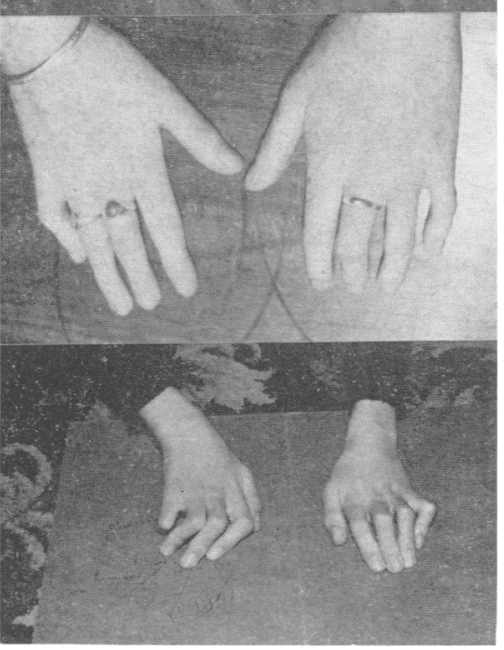

FIG 2 Camptodactyly in (a) III.4, (b) IV.5, (c) $V \cdot 3$, (d) $V \cdot 4,(e) V \cdot 5$.

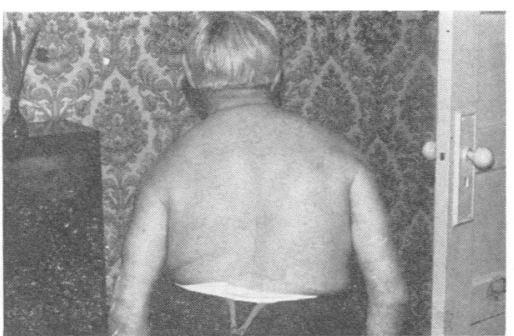

(a)

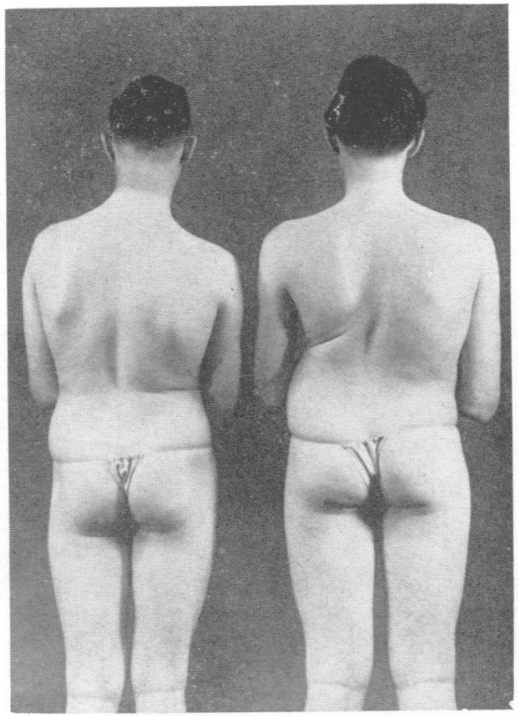

(b)

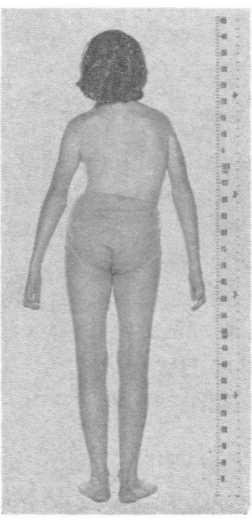

(c)

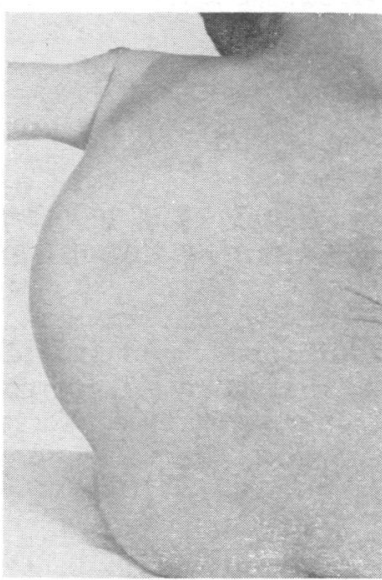

(d)

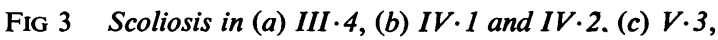
(d) $V \cdot 5$. 
TABLE 2 Camptodactyly syndromes

\begin{tabular}{|c|c|c|c|c|c|}
\hline & Inheritance & Facial features & Hands & Scoliosis & Other features \\
\hline Cantú et $a l^{2}$ & Recessive & $\begin{array}{l}\text { Flat face, } \\
\text { brachycephaly, } \\
\text { wide forehead, myopia }\end{array}$ & Camptodactyly & 一 & $\begin{array}{l}\text { Intrauterine growth } \\
\text { retardation with } \\
\text { proportionate dwarfism }\end{array}$ \\
\hline Emery and Nelson ${ }^{3}$ & Dominant & $\begin{array}{l}\text { High forehead, } \\
\text { flat nasal bridge, } \\
\text { long philtrum, } \\
\text { flat malar region }\end{array}$ & Camptodactyly & - & $\begin{array}{l}\text { Mental retardation } \\
\text { in one }\end{array}$ \\
\hline Goodman et al ${ }^{4}$ & Recessive & $\begin{array}{l}\text { Prominent forehead, } \\
\text { facial asymmetry, } \\
\text { ocular hypertelorism, } \\
\text { small mouth, } \\
\text { long philtrum }\end{array}$ & Camptodactyly & + & 一 \\
\hline Gordon et als & Dominant & Cleft palate & Camptodactyly & - & Club foot \\
\hline
\end{tabular}

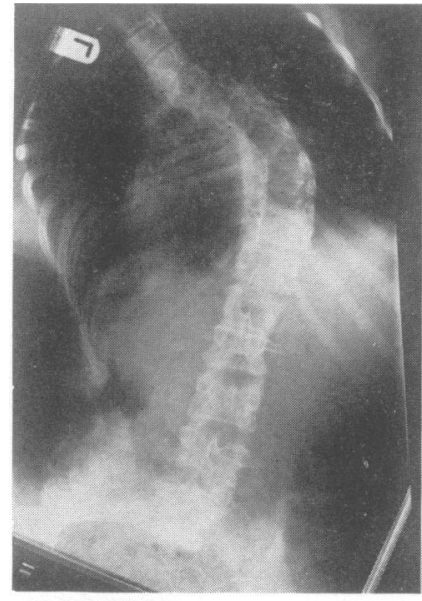

(a)

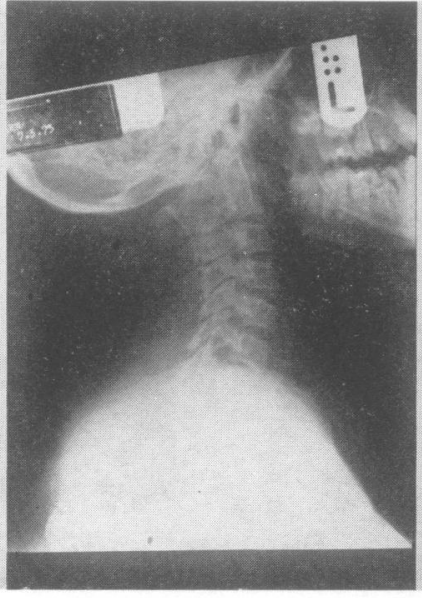

(b)

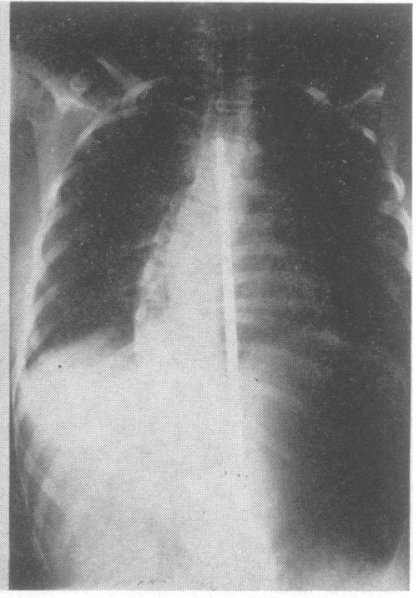

(c)

FIG 4 Radiological findings. (a) IV 1 , severe scoliosis of thoracic spine. (b) $V \cdot 3$, x-ray of neck showing fusion of upper cervical vertebrae. (c) $V \cdot 3, x$-ray showing severe scoliosis of thoracic spine.

deformity), small mouth with inverted $\mathrm{H}$-shaped dimpling of the chin, hypoplasia of the nasal alae, an immobile face, small eye openings, broad nasal bridge, and epicanthus. Neither scoliosis nor torticollis are prominent diagnostic criteria. In the present family, dysmorphic facial features were unremarkable except for one member who had a prominent jaw, wide forehead, and mild hypertelorism.

Other camptodactyly syndromes are listed in table 2. Two are dominantly inherited but are unlike that in the family described here in that neither is associated with scoliosis. Goodman et $\mathrm{al}^{5}$ and Cantú et $a l^{2}$ described recessively inherited syndromes.

The main question that the proband asked was about risks of severe scoliosis and mental retardation 옥 in her offspring. The risk for an affected child is $\square$ clearly $50 \%$ but the risk of mental retardation is probably small. There is, however, a considerable $\bar{N}$ chance that an affected child could have a severe and 5 progressive scoliosis needing operative treatment.

The author is grateful to $\mathrm{Mr} \mathbf{P}$ Webb, FRCS, Consultant Orthopaedic Surgeon, The Hospital for Sick Children, Great Ormond Street, Mr M Pilcher, $\frac{\mathscr{C}}{\Phi}$ the Medical Illustration departments of The Royal $\stackrel{?}{?}$ National Orthopaedic Hospital, Great Portland 0 Street, London, and The Hospital for Sick Children, and Mrs M Bravery for expert help with the preparation of this report. 


\section{References}

1 Temtamy S, McKusick V. The genetics of hand malformations. New York: Liss, 1978.

2 Cantú JM, Rivera H, Nazará Z, Rojas Q, Hernández A García-Cruz D. Guadalajara camptodactyly syndrome. A distinct probably autosomal recessive disorder. Clin Genet 1980;18:153-7.

3 Emery AEH, Nelson MM. A familial syndrome of short stature, deformities of the hands and feet, and an unusual facies. J Med Genet 1970;7:379-82.

4 Goodman RM, Katznelson MBM, Katznelson A.
Camptodactyly with muscular hypoplasia, skeletal dysplasia and abnormal palmar creases: Tel Hashomer camptodactyly syndrome. J Med Genet 1976;13:136-41.

5 Gordon H. Camptodactyly, cleft palate and club foot: a syndrome showing the autosomal-dominant pattern of inheritance. J Med Genet 1969;6:266.

Requests for reprints to Dr M Baraitser, Clinical Genetics Unit, The Hospital for Sick Children, Great Ormond Street, London WC1N 3JH. 